\title{
Endobronchial Nocardiosis associated with Broncholithiasis
}

\author{
W.O. Tam, C.F. Wong, P.C. Wong
}

ABSTRACT: Endobronchial Nocardiosis associated with Broncholithiasis, W.O. Tam, C.F. Wong, P.C. Wong.

Pulmonary nocardiosis is a rare respiratory infection which commonly affects immunocompromised patients but also in immunocompetent hosts. The clinical manifestation is variable and endobronchial nocardiosis is a very rare condition. We report a case of endobronchial nocardiosis associated with the presence of a broncholith. The pathogenesis and the treatment of this condition are discussed below. Monaldi Arch Chest Dis 2008; 69: 4, 183-185.

Keywords: Endobronchial nocardiosis, Broncholithiasis.

Tuberculosis and Chest Unit, Grantham Hospital, Aberdeen, Hong Kong, China.

Correspondence: Dr. Wai On Tam, Tuberculosis and Chest Unit, Grantham Hospital, 125 Wong Chuk Hang Road, Aberdeen, Hong Kong, China,e-mail: tamwaion@yahoo.com

\section{Introduction}

Pulmonary nocardiosis is a rare respiratory infection although the reported incidence has been increasing in recent years. It commonly affects immunocompromised patients but it has also been reported in immunocompetent hosts [1]. The clinical manifestation is variable but the usual radiographic appearance is that of parenchymal lesions which can mimic tuberculosis, fungal infection or malignancy. Endobronchial nocardiosis in which the disease presenting as an endobronchial mass lesion, however, is a very rare condition $[2,3,4]$. We here report a case of endobronchial nocardiosis associated with the presence of a bronchiolith in an immunocompetent female patient.

\section{Case Report}

A 48-year-old lady with an unremarkable past health except for a history of pulmonary tuberculosis with treatment 20 years ago, presented with cough for four months and one episode of haemoptysis. A chest $\mathrm{x}$-ray revealed a right hilar shadow with speck of calcifications (figure 1). A computed tomography showed segmental collapse in lateral segment of right middle lobe (RML) with soft tissue mass lesion with focus of calcification at the origin of the right middle lobe bronchus (figure 2). Multiple calcified normal sized lymph nodes were found in the mediastinum. On fibre-optic bronchoscopic examination, the RML orifice was narrowed with swollen mucosa. Endobronchial biopsy showed chronically inflamed bronchial wall. In the bronchial lumen, there were abundant acute inflammatory exudates containing thin filamentous and fragmented Gram-positive bacteria, resembling Nocardia. Bronchoscopic aspirate for culture was negative. She was put on anti-microbial treat- ment with Imipenem-cilastatin $500 \mathrm{mg}$ intravenously three times a day for two weeks. When she was switched to oral trimethroprim-sulfamethoxazole, she experienced very severe gastrointestinal upset with repeated vomiting despite anti-emetics. Therefore, she had to be switched back to intravenous Imipenem-cilastatin, which was given for another two weeks. There was marked clinical improvement and chest $\mathrm{x}$-rays showed very good resolution of the lesion as well. It was decided that the progress would be observed rather than for further anti-microbial treatment. However, she had relapse of symptoms on follow up two months later and chest x-ray showed relapse of disease at RML. Relapse of endobronchial nocardiosis was confirmed by bronchoscopy showing obliteration of the RML orifice by swollen mucosa and biopsy showing severely inflammed bronchial mucosa with aggregates of thin Gram-positive and weakly acid-fast bacillary organisms. She was then put on intravenous Meropenem $1 \mathrm{gm}$ every 8 hours per day with Amikacin $650 \mathrm{mg}$ daily for 4 weeks. Bronchoscopic reassessment showed marked improvement in the swollen mucosa of RML orifice. A foreign body was found deep inside right middle lobe orifice. It was of stony consistency but it could not be retrieved by forceps despite repeated attempts with only small fragments coming off on biopsy. After the intravenous anti-microbial therapy, she was continued with oral minocycline $100 \mathrm{mg}$ twice daily. However, she complained of poor tolerance to the drug with bitter taste and skin colouration. It was subsequently decided that she would undergo surgery and a right middle lobectomy was performed while she was covered with minocycline. The resected RML showed bronchiectasis with intra-luminal Nocardia. A $1 \mathrm{~cm}$ hard yellow broncholith was present in the proximal lateral seg- 


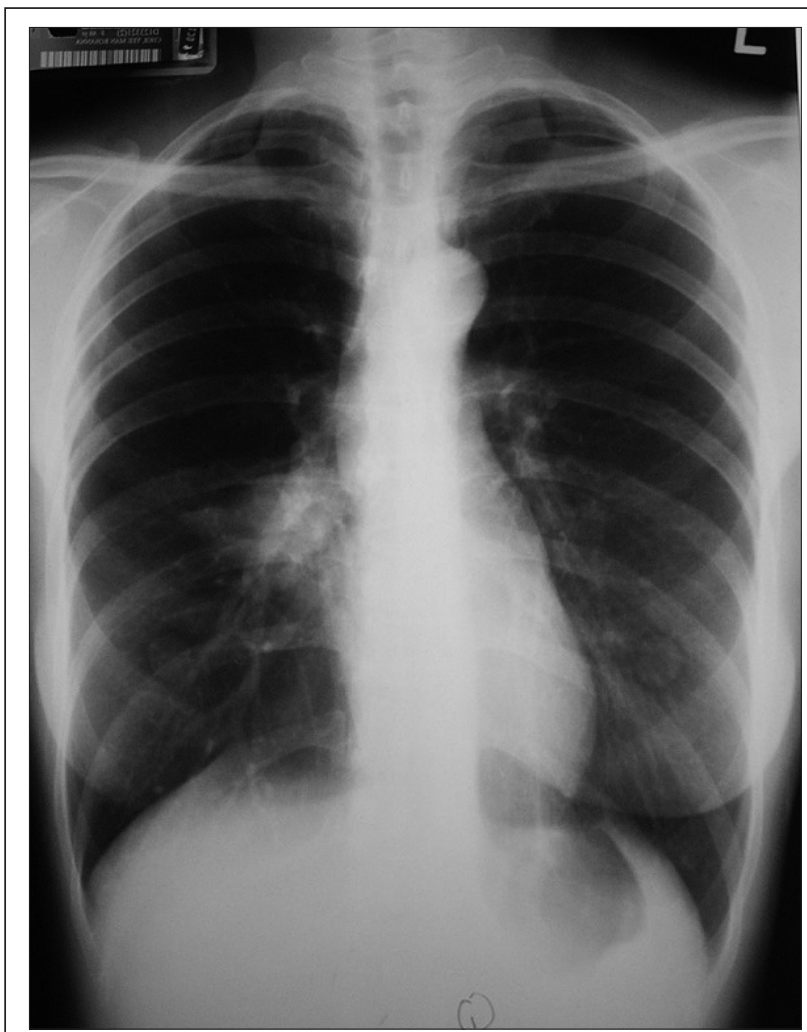

Fig. 1. - Chest X-ray showed a right hilar shadow with speck of calcifications.

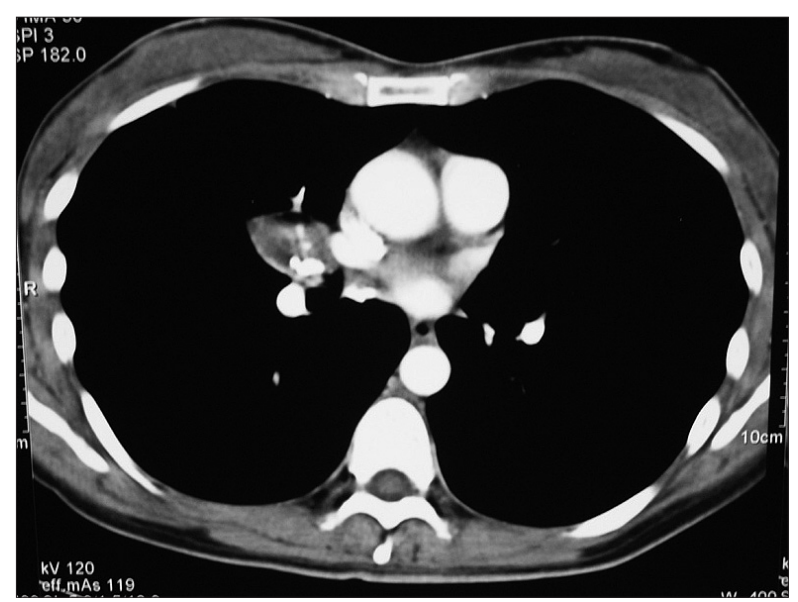

Fig. 2. - Computed tomography showed segmental collapse in lateral segment of right middle lobe (RML) with soft tissue mass lesion with focus of calcification at the origin of the right middle lobe bronchus.

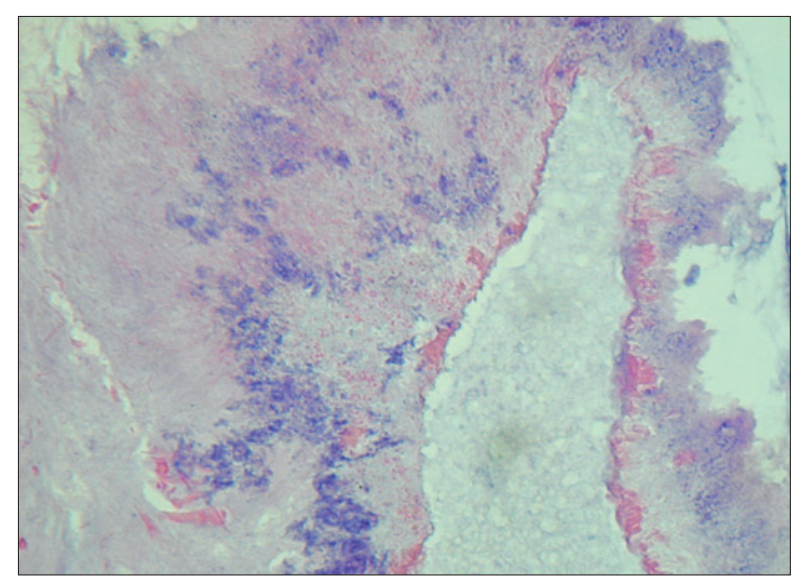

Fig. 3. - Broncholith following de-calcification showed fluffy colonies of Gram-positive filamentous bacillary organisms consistent with Nocardia. Haematoxylin-eosin stain. mental bronchus of RML. Microscopic examination of the broncholith following de-calcification showed fluffy colonies of Gram-positive filamentous bacillary organisms consistent with Nocardia. (figure 3).

She remained well afterwards with no respiratory symptoms and there was no relapse of the disease on follow up.

\section{Discussion}

Nocardia is an uncommon weakly acid-fast, Gram-positive branching filamentous bacterium. It is a common opportunistic infection affecting immunocompromised patients like those having hematological malignancy, HIV infection, post-organ transplant state or prolonged corticosteroid therapy. However, it could also affect immunocompetent patients like our reported case [5]. Nocardia lung infection usually presents as parenchymal disease. Our patient presenting with predominant endobronchial disease with mucosal swelling resulting in obliteration of the lobar bronchus is very rare indeed. It was subsequently found to be associated with the presence of a broncholith. Broncholithiasis has been frequently reported to be associated with Actinomycosis [6, 7]. However, its association with endobronchial nocardiosis has never been reported in medical literature to the best of our knowledge.

Broncholithiasis, defined as the presence of a calcified material within the lumen of a bronchus, is a very rare condition [8]. It is usually formed by erosion and extrusion of a calcified adjacent lymph node into the bronchial lumen [9].

In our patient, the presence of calcified lymph nodes in the mediastinum might suggest this etiology. The endobronchial nocardiosis might represent a secondary infection with the broncholith acting as a nidus of infection. However, the presence of nocardia colonies only in the broncholith on pathological examination and the absence of peri-bronchial lymph nodes might lead one to speculate its formation to be not from erosion form adjacent lymph node but rather from de novo calcification of the chronic endobronchial nocardia infection. This "chicken or egg first?" controversy has been well discussed in those cases of broncholithiasis associated with endobronchial actinomycosis in the literature [10]. Our case might represent another case with such a controversy but with a different but closely akin infection.

On the treatment of our patient, surgical resection is seldom required for either nocardiosis or broncholithiasis alone. The mainstay of treatment for nocardiosis is prolonged anti-microbial treatment with sulphonamides usually in form of sulfamethoxazole-trimethoprim. Other useful anti-microbials include minocycline, imipenam, amikicin and linezolid [11]. For broncholithiasis, asymptomatic patients could be put on observations. Alternatively, it could be removed by either fibre-optic or rigid bronchoscopy. Although many bronchoscopists may prefer rigid bronchoscopy due to potential risk of catastrophic 
bleeding, it has been reported that both methods can be considered safe and effective [12]. Surgical resection might be indicated for intractable cough, haemoptysis, recurrent infection or fistula [13]. In our patient, with the concomitant presence of both conditions and the failure of bronchsocopic removal of the broncholith, and in view of the fact that the patient could not tolerate antimicrobial treatment well, surgical resection proved to be a very effective treatment by surgically removing both the infection as well as the associated broncholith.

\section{References}

1. Corti ME, Villafane-Fioti MF. Nocardiosis: a review. Int J Infect Dis 2003; 7: 243-50.

2. McNeil KD, Johnson DW, Oliver WA. Endobronchial nocardial infection. Thorax 1993; 48: 1281-2.

3. Casty FE, Wencel M. Endobronchial nocardiosis. Eur Respir J 1994; 7: 1903-5.

4. Kumar N, Ayinla R. Endobronchial pulmonary nocardiosis. Mt Sinai J Med 2006; 73: 617-9.

5. Menendez R, Cordero PJ, Santos M, Gobernado M,
Marco V. Pulmonary infection with Nocardia species: a report of 10 cases and review. Eur Respir J 1997; 10: 1542-6.

6. Seo JB, Lee JW, Ha SY Park JW, Jeong SH, Park GY. Primary endobronchial actinomycosis associated with broncholithiasis. Respiration 2003; 70: 110-3.

7. Kim TS, Han J, Koh WJ, et al. Endobronchial actinomycosis associated with broncholithiasis: CT findings for nine patients. Am J Roentgenol 2005; 185: 347-353.

8. Nollet AS, Vansteenkiste JF, Demedts MG. Broncholithiasis: rare but still present. Respir Med 1998; 92: 963-5.

9. Seo JB, Song KS, Lee JS, et al. Broncholithiasis: reviews of the causes with radiologic-pathologic correlation. Radiographics 2002 Oct; 22 Spec No: S199-213.

10. Boujaoude ZC, Aboujaoude RN, Pratter MR, Bartter T. Actinomyces in a Broncholith; Chicken v. Egg. Chest 2003 124: 270.

11. Matulionyte R, Rohner P, Uckay I, Lew D, Garbino J. Secular trends of nocardia infection over 15 years in a tertiary care hospital. J Clin Pathol 2004; 57: 807-12.

12. Olson EJ, Utz JP, Prakash UB. Therapeutic bronchoscopy in broncholithiasis. Am J Respir Crit Care Med 1999 160: 766-70.

13. Poatris K, Miller DL, Victor F, et al. Role of Surgical Resection in Broncholithiasis. Ann Thorac Surg 2000; 70: 248-52.

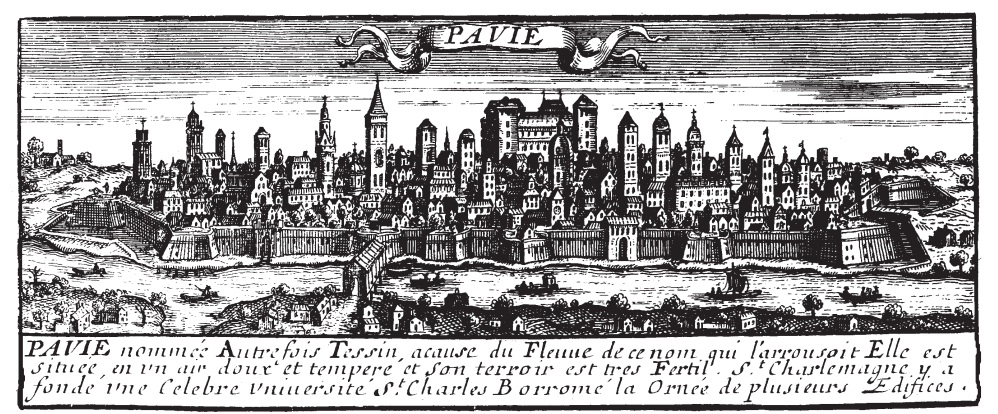

